\title{
Incidence and predictors of tuberculosis among HIV-positive adults on antiretroviral therapy at Debre Markos referral hospital, Northwest Ethiopia: a retrospective record review
}

Belisty Temesgen ${ }^{1}$, Getiye Dejenu Kibret ${ }^{2}$, Nakachew Mekonnen Alamirew², Mamaru Wubale Melkamu', Yitbarek Tenaw Hibstie ${ }^{1}$, Pammla Petrucka ${ }^{3,4}$ and Animut Alebel ${ }^{2,5^{*}}$ (D)

\begin{abstract}
Background: Tuberculosis is the leading cause of morbidity and mortality among people living with human immunodeficiency virus. Almost one-third of deaths among people living with human immunodeficiency virus are attributed to tuberculosis. Despite this evidence, in Ethiopia, there is a scarcity of information regarding the incidence and predictors of tuberculosis among people living with HIV. Thus, this study assessed the incidence and predictors of tuberculosis among HIV-positive adults on antiretroviral therapy.

Methods: This study was a retrospective record review including 544 HIV-positive adults on antiretroviral therapy at Debre Markos Referral Hospital between January 1, 2012 and December 31, 2017. The study participants were selected using a simple random sampling technique. The data extraction format was adapted from antiretroviral intake and follow-up forms. Cox-proportional hazards regression model was fitted and Cox-Snell residual test was used to assess the goodness of fit. Tuberculosis free survival time was estimated using the Kaplan-Meier survival curve. Both the bi-variable and multivariable Cox-proportional hazard regression models were used to identify predictors of tuberculosis.
\end{abstract}

Results: In the final analysis, a total of 492 HIV-positive adults were included, of whom, 83 (16.9\%) developed tuberculosis at the time of follow-up. This study found that the incidence of tuberculosis was 6.5 (95\% Cl: 5.2, 8.0) per 100-person-years (PY) of observation. Advanced World Health Organization clinical disease stage (III and IV) (AHR: 2.1, 95\% Cl: 1.2, 3.2), being ambulatory and bedridden (AHR: 1.8, 95\% Cl: 1.1, 3.1), baseline opportunistic infections (AHR: 2.8, 95\% Cl: 1.7, 4.4), low hemoglobin level (AHR: 3.5, 95\% Cl: 2.1, 5.8), and not taking Isonized Preventive Therapy (AHR: $3.9,95 \% \mathrm{Cl}: 1.9,7.6$ ) were found to be the predictors of tuberculosis.

Conclusion: The study found that there was a high rate of tuberculosis occurrence as compared to previous studies. Baseline opportunistic infections, being ambulatory and bedridden, advanced disease stage, low hemoglobin level, and not taking Isonized Preventive Therapy were found to be the predictors of tuberculosis. Therefore, early detection and treatment of opportunistic infections like tuberculosis should get a special attention.

Keywords: Debre Markos, HIV, Incidence, Predictors, Tuberculosis

* Correspondence: animut.a23@gmail.com

${ }^{2}$ College of Health Science, Debre Markos University, P.O. Box 269, Debre

Markos, Ethiopia

${ }^{5}$ Faculty of Health, University of Technology Sydney, Sydney, Australia

Full list of author information is available at the end of the article

(c) The Author(s). 2019 Open Access This article is distributed under the terms of the Creative Commons Attribution 4.0 International License (http://creativecommons.org/licenses/by/4.0/), which permits unrestricted use, distribution, and reproduction in any medium, provided you give appropriate credit to the original author(s) and the source, provide a link to the Creative Commons license, and indicate if changes were made. The Creative Commons Public Domain Dedication waiver (http://creativecommons.org/publicdomain/zero/1.0/) applies to the data made available in this article, unless otherwise stated. 


\section{Background}

Tuberculosis (TB) is the leading cause of morbidity and mortality among People Living with Human Immunodeficiency Virus (PLHIV) [1]. PLHIV are 20 times more likely to develop TB as compared to those without HIV [2, 3]. In 2017, an estimated 10 million people developed TB with 1.6 million succumbing to the disease, of whom, 9\% were PLHIV. In the same year, approximately 300,000 people died due to Acquired Immunodeficiency Syndrome (AIDS)-related TB worldwide, with $72 \%$ of these deaths occurring in Africa [4]. Sub-Saharan Africa (SSA) bears the highest (74\%) burden of all TB cases $[5,6]$.

Ethiopia is one of the SSA countries with the highest prevalence of TB/HIV co-infection and ranked seventh among the world's 30 highest TB burden countries. In 2017, according to the Centers for Diseases Control (CDC) and Prevention report, the incidence rate of TB in Ethiopia was 164 cases per 100,000 population including approximately 7\% who were PLHIV. In the same year, the mortality rate of TB patients in Ethiopia was 24 per 100,000 population [7]. A range of interventions have been implemented at the global and local levels to tackle this challenge. For example, integrated management of TB/HIV co-infection in a single health facility via using a single health care provider to deliver integrated therapy and manage both diseases efficiently. In addition, a scale-up of Antiretroviral Therapy (ART) was introduced aimed to reduce HIV-related morbidity and mortality as well as to increase the survival of HIVinfected patients [8-11].

The Ethiopian government has adapted and implemented different strategies to reduce TB related morbidity and mortality among PLHIV. For example, the Ministry of Health $(\mathrm{MOH})$ decentralized TB/HIV co-infection care services from hospitals to health centers and strengthened referral systems to improve TB care and treatment at the community level [12]. In addition, early initiation of ART and early screening of TB, prior to provision of Isonized Preventive Therapy (IPT) [13] and Co-trimoxazole Prophylactic Therapy $(\mathrm{CPT})$, were interventions implemented to reduce the incidence of TB among PLHIV [14-18].

Although the incidence of TB among HIV-positive adults in Ethiopia has improved due to different interventions, it remains the major cause of death among PLHIV. Previous Ethiopian studies have documented that the incidence of $\mathrm{TB}$ among HIV-positive adults ranged from 3.3 per 100 PY of observation in Addis Ababa [19] to 8.6 per 100 PY of observation in Afar Region [20]. Previous Ethiopian-based studies have identified a number of contributing factors to increasing TB occurrence among HIV-positive adults including household family size between three to four individuals, cigarette smoking, not taking IPT, not taking CPT, low baseline CD4 counts, advanced World Health Organization
(WHO) clinical disease stages (Stage II or IV), and having a history of diabetic mellitus [20-22].

The Ethiopian government targeted a reduction of TB related deaths by $90 \%$ and TB incidence by $80 \%$ by 2030 from 2015 levels [23]. To evaluate this ambitious plan, current and up-to-date information related to the occurrence of TB is vital. Therefore, this retrospective record review explored the incidence of TB among HIV-positive adults at Debre Markos Referral Hospital. Results obtained from this study will contribute to evidence for policy makers and program planners working at various levels of TB control programs, as well as informing health care professionals in the areas of TB control and prevention.

\section{Methods}

\section{Study design, area, and period}

A retrospective record review was conducted at Debre Markos Referral Hospital of applicable patient records from between January 1, 2012 and December 31, 2017. Debre Markos Referral Hospital is located in Debre Markos Town, which is located $299 \mathrm{~km}$ from Addis Ababa, the capital city of Ethiopia and $265 \mathrm{~km}$ from Bahir-Dar, the main city of Amhara Regional State. The hospital serves more than 3.5 million people in East Gojjam Zone and neighboring areas. Apart from other services, the hospital has been providing ART follow-up care services since 2005. In the hospital, the recorded number of HIV-positive people ever started ART was 3716, of whom, 1, 569 HIV-positive adults started ART care between January 1, 2012 and December 31, 2017.

\section{Population}

All HIV-positive adults ever started ART at Debre Markos Referral Hospital and who had at least 1 month of ART follow-up from January 1, 2012 to December 31, 2017 were the target population for this study. All HIVpositive adults ever started ART from January 1, 2012 to December 31, 2017, however, HIV-positive adults on ART who had TB at the beginning of the follow-up and those who had incomplete baseline data for important variables (i.e., WHO stage, CD4 counts, hemoglobin, (Hgb), IPT, CPT and level of ART adherence) were excluded from the study.

\section{Sample size determination and sampling procedures}

The minimum required sample size for this study was calculated using a sample size determination formula for survival analysis using Stata $^{\mathrm{TM}}$ Version 13 statistical software by considering CD4 count, functional status, and WHO clinical staging as major exposure variables. It was calculated by considering the following statistical assumptions: two-sided significant level $(\alpha)$ of $5 \%$, power $80 \%, \mathrm{Z}_{\mathrm{a} / 2}=$ value at $95 \% \mathrm{CI}=1.96, \mathrm{q}_{1}$ : proportion of subjects that are in group 1 (exposed), qo: proportion of 
subjects that are in group 2 (unexposed); $1-\mathrm{q}_{1}$, HR: hazard ratio, and probability of event (E) for functional status were taken from a study conducted at the University of Gondar Teaching Hospital (0.33) [21]. Finally, the calculated sample size for this study was 544. To select the study participants, the records of all HIV-positive adults ever started ART and recorded from January 1, 2012 to December 31, 2017 were sorted. Then, the study participants were selected using a simple random sampling technique through computer-generated numbers. We selected this follow-up period for two reasons:: first, we intended to have a nearest 6 years of follow-up; and second, to take advantage of standardized ART documentation and reporting formats used during this period.

\section{Data collection tool and procedures}

The data extraction tool was prepared from the ART entry and follow-up forms. To ensure data quality, before data collection, the data extraction tool was prepared carefully from a standardized ART intake and follow-up forms. Furthermore, before the beginning of data collection, we verified consistency between data recording systems and the prepared checklist by randomly selecting and completing a few chart reviews which resulted in minor amendments of the data collection tool. Three BSc nurses who have been working in the ART clinic of Debre Markos Referral Hospital collected the data. Two days of training was given for both data collectors and supervisor concerning the data collection tool and collection process. The supervisor and principal investigators performed a strict follow-up and supervision throughout the entire data collection period. The most recent laboratory test results before starting ART were considered as a baseline value. If there were no pre-treatment laboratory test results, obtained at the time of ART initiation, test results done within 1 month of ART initiation were used as a baseline data. In case of two results obtained within a month, the mean value was computed and taken as a baseline.

\section{Measurements}

The dependent variable was the time to develop TB. The predictor variables were: Socio-demographic characteristics (age, sex, marital status, residence, family size, level of education, and occupation), Baseline clinical and laboratory characteristics (WHO clinical stage, CD4 cell count, hemoglobin level, history of TB, and history of opportunistic infections (OIs) and body mass index (BMI), and ART and other medication-related characteristics (type ART regimens, regimen change, ART side effects, ART adherence, IPT, and CPT).

The focus of this study was on health care documentation of the event (the occurrence of TB) for HIVpositive adults in cases where TB developed after ART initiation until the end of the study. This was ascertained by review of patient records. However, the study participants were classified as censored in either of the following conditions: if lost to follow-up or died before developing TB or if alive at the end of the study, but didn't develop TB and took anti-TB medications. These elements were ascertained by reviewing patient records. In this study, lost to follow-up was defined as an HIVpositive patient missing an ART appointment for one to 3 months [24]. Additionally, adherence was classified as good, fair, or poor, according to the percentage of drug dosage calculated from a monthly total dose of ART drugs; hence, good was reported if equal to or greater than $95 \%$ or $\leq 3$ dose missing per month, fair if $85-94 \%$ or 4-8 dose missing per month, or poor if less than $85 \%$ or $\geq 9$ dose missing per month [25]. Furthermore, low hemoglobin level was defined as Hgb level less than to $10 \mathrm{~g} / \mathrm{dl}$. Finally, opportunistic infections were diagnosed if HIV-positive adults developed any morbidities after starting ART, as documented by the health care professionals.

\section{Data processing and analysis}

Data were entered using EPI-data ${ }^{\mathrm{TM}}$ Version 4.2, and analyzed using STATA Version 13 statistical software. Patient's follow-up characteristics for continuous data were described in terms of central tendency, dispersion, and frequency distribution for categorical data. At the end of follow-up, the outcome of each study participant was dichotomized into censored or event. The necessary assumption of Cox proportional hazard regression model was checked using Schoenfeld residual and Log-Log plot tests. In addition, the model goodness of fit was assessed using Cox-Snell residual test and model with the least value of Akaike's information criteria selected as the best model. The Kaplan Meier survival curve was used to estimate the TB free survival time of HIV-positive adults on ART. Log rank test was used to compare the survival curves of different categorical explanatory variables. Bivariable Cox-proportional hazard regression model was used to screen variables for the final model. Variables having $p$-value $\leq 0.25$ in the bi-variable analysis were fitted into the multivariable Cox-proportional hazard regression model. Finally, adjusted hazard ratio with its corresponding 95\% confidence interval was reported to declare the presence of significant association between the explanatory and outcome variables.

\section{Results}

Socio-demographic characteristics of participants

After removal of fifty-two (52) incomplete records, 492 HIVpositive adult charts were included in the final analysis. The median age of the entire cohort was 33.0 years (IQR: 27, 40 years). More than half (53.6\%) of the study participants were 
female and more than three fourth $(78.86 \%)$ of the participants disclosed their HIV status (Table 1).

\section{Baseline clinical, laboratory, ART, and other medication- related information}

Clinically, more than half $(61.8 \%)$ of the study participants were classified as WHO clinical stage I/II. The mean baseline CD4 cell count of the study participants was 252.7 cell $/ \mathrm{mm}^{3}$ (SD: \pm 9.5 cell $/ \mathrm{mm}^{3}$ ). In addition, the majority (90.43\%) of study participants had a $\mathrm{Hgb}$ of $10 \mathrm{~g} / \mathrm{dl}$ and more. Almost, one-third (32.93\%) of the participants had baseline OIs. Regarding functional status, the majority $(81.2 \%)$ of study participants were classified as working functional status. At baseline, less than onethird (29.47\%) of the participants were undernourished (BMI < 18.5). About $5 \%$ of the participants had a history of initial regimen change during follow-up. The majority (95.53\%) of participants had a history of good adherence. Moreover, the majority (85.98\%) of participants took CPT; however, only $36.38 \%$ received IPT (Table 2 ).

\section{Incidence of tuberculosis}

In this study, a total of 492 study participants were followed for a different period, contributing a cohort of 1285.54 PY of observation. During the follow-up period, $83(16.9 \%)$ of the study participants experienced TB with an overall incidence rate of TB of 6.5 (95\% CI: 5.2, 8.0) per $100 \mathrm{PY}$ of observation. A $14.5 \%$ TB incidence rate (95\% CI: 11.3, 18.7 per 100 PY) was highest in the first year of follow-up, decreasing in subsequent years. The cumulative probability of ТВ free survival at the end of 1 year, two, three, four, five and 6 years were $0.87,0.84$, $0.82,0.80,0.79$, and 0.78 respectively. The mean TB free survival time of the entire follow up was 60.8 months (95\% CI: 58.2, 63.1 months) (Fig. 1).

\section{Bi-variable and multivariable cox-regression analysis}

Through multivariable Cox-regression analysis, advanced WHO clinical stages (III and IV), baseline OIs, being ambulatory and bedridden, low hemoglobin level $(<10$ $\mathrm{g} / \mathrm{dl}$ ), and not taking IPT were found to be significant predictors of TB. In this study, the hazard of developing TB among HIV-positive adults on ART who were classified as WHO clinical stage III and IV at baseline was 2.1 (95\% CI: 1.2, 3.2) times higher as compared to those classified as WHO Stages I and II. Similarly, the hazard of developing TB among HIV-positive adults classified as ambulatory and bedridden at baseline was 1.8 (95\% CI: 1.1, 3.1) times higher as compared to those who were classified as working functional status. In addition, the hazard of developing TB among patients who had OIs at baseline was 2.8 times (95\% CI: 1.7, 4.4) higher as compare to those who were OIs free at baseline. Furthermore, the hazard of developing $\mathrm{TB}$ among patients
Table 1 Socio-demographic characteristics of patients on chronic HIV care at Debre-Markos Referral Hospital, Northwest Ethiopia

\begin{tabular}{lll}
\hline Characteristics & Frequency $(\mathrm{N})$ & Percentage (\%) \\
\hline Age & 62 & 12.6 \\
15-24 year & 199 & 40.4 \\
25-34 year & 151 & 30.7 \\
35-44 year & 80 & 16.3 \\
$>$ 45 year & Sex & \\
& 228 & 46.3 \\
Male & 264 & 53.7 \\
Female &
\end{tabular}

$\begin{array}{lcc} & \text { Marital status } \\ \text { Single } & 66 & 13.4 \\ \text { Married } & 268 & 54.5 \\ \text { Divorced } & 126 & 25.6 \\ \text { Widowed } & 32 & 6.5 \\ & & \\ \text { Orthodox } & \text { Religion } \\ \text { Others } & 477 & 97.0 \\ & 15 & 3.0\end{array}$

Educational status

$\begin{array}{lll}\text { No formal education } & 145 & 29.5 \\ \text { Primary } & 115 & 23.4 \\ \text { Secondary } & 144 & 29.3 \\ \text { Tertiary } & 86 & 17.4 \\ \text { Not recorded } & 2 & 0.4\end{array}$

Employed

Occupation

Unemployed

\section{0}

22.6

376

77.4

Within catchment area

Residence

Out of catchment area

464

94.3

28

5.7

\section{Disclosure status}

\section{Disclosed}

388

78.9

Not disclosed

104

21.1

$\begin{array}{lll}<=3 & 389 & 82.7 \\ >3 & 85 & 17.3\end{array}$

presenting with Hgb level less than $10 \mathrm{~g} / \mathrm{dl}$ during ART initiation was 3.5 (95\%CI: 2.1, 5.8) times higher than those with $\mathrm{Hgb}$ levels greater than or equal to $10 \mathrm{~g} / \mathrm{dl}$. 
Table 2 Baseline clinical, Laboratory, ART and other medication related information of HIV patients on chronic HIV care at Debre-Markos Referral Hospital, Northwest Ethiopia

\begin{tabular}{lcc}
\hline Characteristics & Frequency $(\mathrm{N})$ & Percentage (\%) \\
\hline WHO clinical staging & & \\
I / II & 304 & 61.8 \\
III /IV & 188 & 38.2 \\
& & \\
$<100$ & CD4 count & \\
$100-200$ & 113 & 23.0 \\
$201-350$ & 123 & 25.1 \\
$>=351$ & 140 & 28.5 \\
& 115 & 23.4
\end{tabular}

\section{Functional status}

$\begin{array}{lll}\text { Working } & 418 & 85.1 \\ \text { Ambulatory /bed redden } & 73 & 14.9\end{array}$

\section{CD4 cell count}

Hemoglobin level

$$
\begin{aligned}
& <10 \mathrm{~g} / \mathrm{dl} \\
& >=10 \mathrm{~g} / \mathrm{gl}
\end{aligned}
$$$$
44
$$$$
416
$$

Underweight

Not Underweight

$B M I / M U A C$

$$
145
$$

347

\section{Eligible criteria}

WHO stage

Both

Test \& treat

Not recorded

$$
\begin{aligned}
& 1 d=\text { ZDV-3TC EFV } \\
& 1 c=\text { ZDV-3TC- NVP } \\
& 1 e=\text { TDF-3TC-EFV } \\
& 1 f=\text { TDF-3TF-NVP } \\
& \text { Other }
\end{aligned}
$$

\begin{tabular}{lcc}
$<10 \mathrm{~g} / \mathrm{dl}$ & 44 & 9.6 \\
$>=10 \mathrm{~g} / \mathrm{gl}$ & 416 & 90.4 \\
& & \\
Underweight & 145 & 29.5 \\
Not Underweight & 347 & 70.5 \\
& & \\
CD4 cell count & 199 & \\
WHO stage & 49 & 40.5 \\
Both & 116 & 10.0 \\
Test \& treat & 89 & 23.6 \\
Not recorded & 38 & 18.2 \\
& & 7.7 \\
1d $=$ ZDV-3TC EFV & Initial regimen & \\
1C = ZDV-3TC- NVP & 11 & 2.2 \\
1e = TDF-3TC-EFV & 36 & 7.3 \\
1f $=$ TDF-3TF-NVP & 423 & 86.2 \\
Other & 15 & 3.1 \\
& 6 & 1.2 \\
Yes & & \\
No & & \\
\hline
\end{tabular}

\section{1}

\section{6} 6

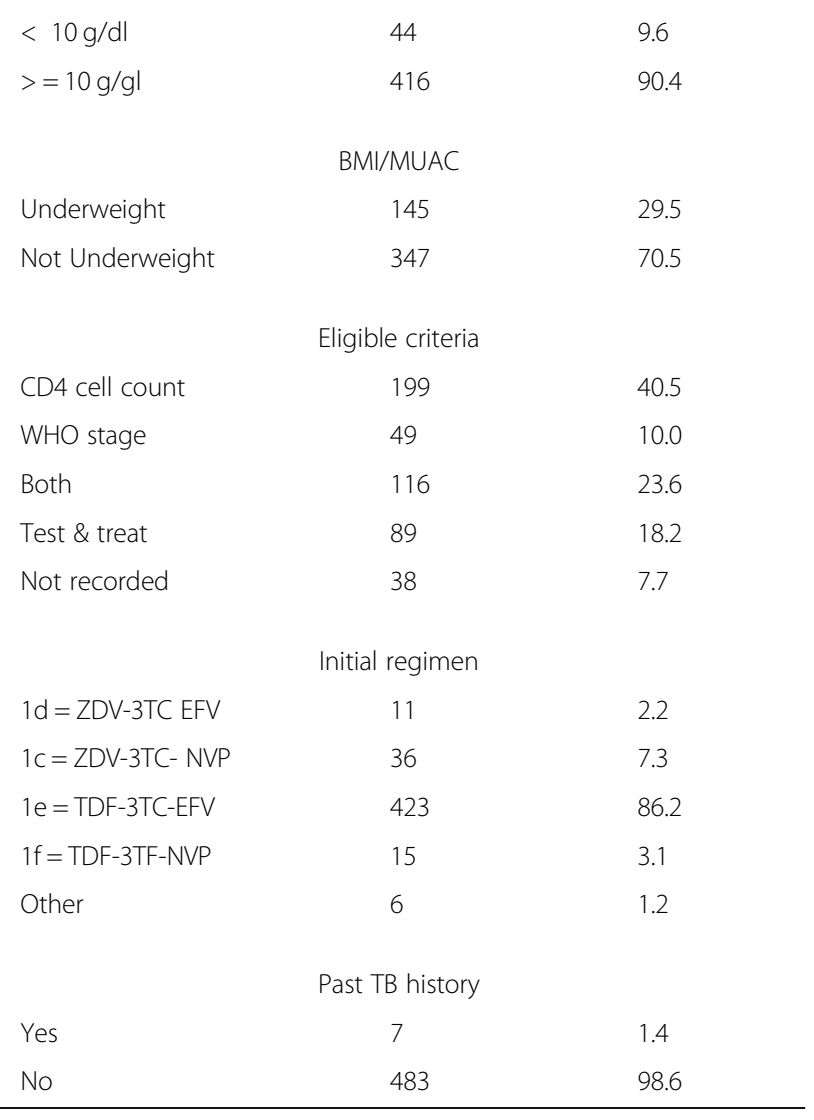

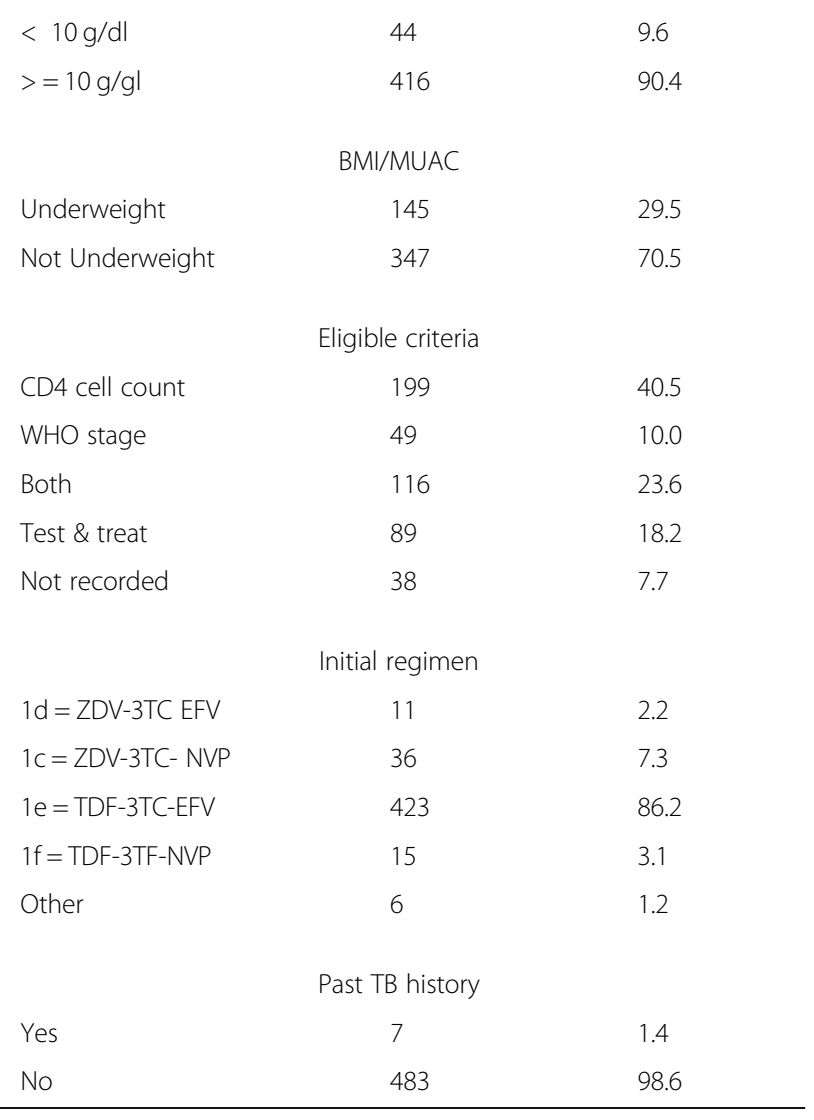

Lastly, HIV-positive adults on ART who did not take IPT were 3.9 (95\% CI: 1.9, 7.6) times more likely to develop TB as compared to those who took IPT (Table 3). The goodness of fit for the model was assessed using a Cox-Snell residual test (Fig. 2).

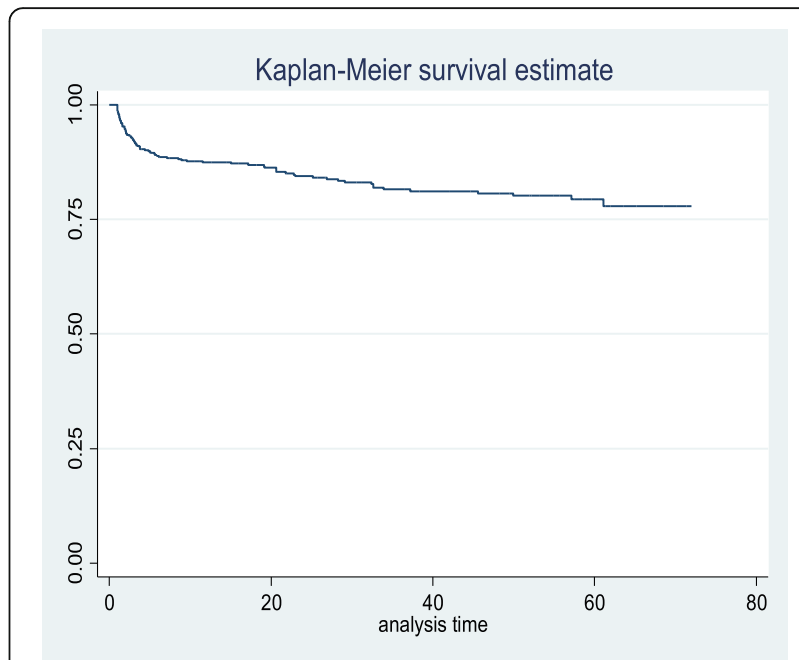

Fig. 1 The overall Kaplan-Meier survival curve of TB free survival time of HIV-positive adults on ART car at Debre-Markos Referral Hospital, Northwest Ethiopia

\section{Discussion}

Tuberculosis is a major public health challenge and remains the most commonly diagnosed OI among PLHIV [3]. Therefore, we conducted this retrospective record review to determine the incidence and predictors of $\mathrm{TB}$ among HIV-positive adults at Debre Markos Referral Hospital. In this study, the overall incidence of TB among HIV-positive adults at Debre Markos Referral Hospital was 6.5 (95\% CI: $5.2,8.0)$ per 100 PY of observation. This finding is in line with previous Ethiopian studies conducted in Gondar (7.89 cases per $100 \mathrm{PY}$ ) [21] and Arba Minch (5.36 cases per 100 PY) [22]. On the other hand, this finding is higher than studies from developed as well as developing countries including: Brazil (2.28 cases per 100 PY) [26], Nigeria (0.57 cases per 100 PY) [27] and Tanzania (4.4 cases per $100 \mathrm{PY)} \mathrm{[28].}$

The higher incidence of TB in this study may be attributed to the differences in follow-up period, sample size, characteristic of study participants, and difference in TB prevalence [18]. For example, the median followup period for a study conducted in Tanzania [28] was 2 years, whereas, in this study, it was 6 years. It is well understood that as the follow-up period increases, the number of events also increases. Additional possible explanation for the above variations could be due to the differences in characteristic of study participants. In this regard, a study done in Tanzania included all HIVpositive patients-initiated ART in all health facilities [28]. However, our study was conducted at a referral hospital providing tertiary level services for patients referred from health centers or general hospitals who are often experiencing advanced disease stage and are at higher risk of developing TB [29]. 
Table 3 Bi-variable and multivariable Cox-regression analysis to identify the predictors of tuberculosis among HIV positive adults on ART care at Debre-Markos Referral Hospital, Northwest Ethiopia

\begin{tabular}{|c|c|c|c|c|}
\hline \multirow[t]{2}{*}{ Variables } & \multicolumn{2}{|c|}{ Survival status } & \multirow[t]{2}{*}{ CHR $(95 \% \mathrm{Cl})$} & \multirow[t]{2}{*}{ AHR $(95 \% \mathrm{Cl})$} \\
\hline & Event & Censored & & \\
\hline \multicolumn{5}{|l|}{ Sex } \\
\hline Male & 47 & 181 & $1.6(1.12 .5)$ & $1.2(0.8,2.0)$ \\
\hline Female & 36 & 228 & 1 & 1 \\
\hline \multicolumn{5}{|l|}{ CD4 cell count } \\
\hline$<200 \mathrm{cell} / \mathrm{mm}^{3}$ & 55 & 180 & $2.2(1.4,3.4)$ & $1.3(0.8,2.1)$ \\
\hline$>=200 \mathrm{cell} / \mathrm{mm}^{3}$ & 28 & 228 & 1 & 1 \\
\hline \multicolumn{5}{|l|}{ WHO clinical staging } \\
\hline Stage I and || & 26 & 278 & 1 & 1 \\
\hline Stage III and IV & 57 & 131 & $4.0(2.5,6.4)$ & $2.1(1.2,3.2)^{a}$ \\
\hline \multicolumn{5}{|l|}{ Functional status } \\
\hline Working & 51 & 367 & 1 & 1 \\
\hline Ambulatory \& bedridden & 32 & 41 & $5.0(3.2,7.8)$ & $1.8(1.1,3.1)^{a}$ \\
\hline \multicolumn{5}{|l|}{$\mathrm{BMI} / \mathrm{MUAC}$} \\
\hline Underweight & 32 & 113 & 1.6(1.1.2.6) & $1.3(0.8,2.1)$ \\
\hline Not Underweight & 51 & 296 & 1 & 1 \\
\hline \multicolumn{5}{|l|}{ Hemoglobin level } \\
\hline$<10 \mathrm{~g} / \mathrm{dl}$ & 27 & 20 & $6.7(4.2,10.7)$ & $3.5(2.1,5.8)^{\mathrm{a}}$ \\
\hline$\geq 10 \mathrm{~g} / \mathrm{dl}$ & 56 & 383 & 1 & 1 \\
\hline \multicolumn{5}{|l|}{ Opportunistic infection } \\
\hline Yes & 51 & 111 & $3.7(2.4,5.7)$ & $2.8(1.7,4.4)^{\mathrm{a}}$ \\
\hline No & 32 & 298 & 1 & 1 \\
\hline \multicolumn{5}{|l|}{ CPT } \\
\hline Yes & 69 & 354 & 1 & 1 \\
\hline No & 14 & 55 & $1.6(0.9,2.8)$ & $1.4(0.8,2.5)$ \\
\hline \multicolumn{5}{|l|}{ IPT } \\
\hline Yes & 10 & 169 & 1 & 1 \\
\hline No & 73 & 240 & $4.8(2.5,9.3)$ & $3.9(1.9,7.6)^{a}$ \\
\hline
\end{tabular}

${ }^{\text {aSignificant predictors and data are in bold }}$

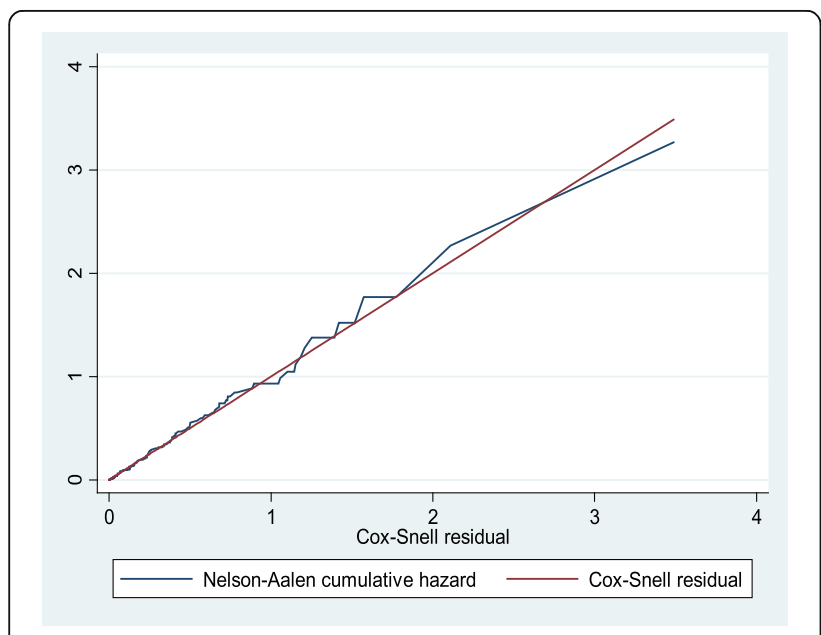

Fig. 2 The goodness of fit test for Cox-proportional hazard regression model
However, the incidence rate of TB obtained from this study is lower than a study conducted in Afar region, Northeast Ethiopia (8.6 cases per 100 PY) [20]. This variation could be explained by the difference in study settings, since this study was conducted at one referral hospital, whereas the study conducted in Afar region was done in three hospitals and two health centers. As the Ethiopian TB care strategy currently is decentralized patients commonly visit health centers before referred to hospitals; hence, including health centers as a study stetting will increase the case detection rate, which ultimately increases the incidence of TB [20]. Another possible explanation for this variation could be due to the difference in characteristics of study participants during ART initiation. In this study, about $38.2 \%$ of the study participants were classified as WHO clinical stage 
III or IV, but, in a study conducted in Afar health facilities, more than half $(53.4 \%)$ of the study participants were classified as WHO stage III or IV [16]. As the WHO clinical disease stage becomes more advanced, the risk of OIs developing and recurring including TB simultaneously increases.

Regarding the time to develop TB, about $60 \%$ of $\mathrm{TB}$ cases developed TB in the first 6 months of follow-up. This finding is in line with studies conducted in different parts of Ethiopia and elsewhere [18, 20-22, 26-28]. The higher incidence of TB in early phase of ART could be associated with the progression of the disease from latent to active TB potentially remaining undetectable during early phase of ART [30]. Immune reconstitution inflammatory syndrome was very common in the first 2-12 weeks of ART. It highly increases the protective responses of the immune system, which leads to a typical inflammatory condition which creates a higher chance of latent TB infection to become active TB [31]. Moreover, the main actions of HAART are increasing CD4 cell counts and decreasing viral load, which ultimately improves the immune function and reduces the OIs occurrence including TB [32].

In this study, advanced WHO clinical disease stage (III and IV) was found to be an important predictor of TB among HIV-positive adults on ART. This finding is consistent with studies previously conducted in different regions of Ethiopia [21, 28, 29, 33-35], and South Africa [30]. as WHO clinical disease staging becomes more advanced, the risk of developing and recurrence of OIs including TB simultaneously increased [29].

Being ambulatory and bedridden was also another predictor of tuberculosis among HIV positive adults. Accordingly, those who were classified as ambulatory and bedridden were more likely to develop TB as compared to those who were classified as working. This finding is consistent with different studies conducted in Ethiopia [20, 21, 34]. Being bedridden and ambulatory functional status are more prone to develop TB because patients become bedridden and ambulatory due to advanced disease stage and more immune compromised stage of HIV [21]. The other possible explanation could be due to restriction from physical activities and inability to perform daily tasks which, indirectly, compromise the immune system [20] and may increase the risk of other OIs and TB.

In this study, patients who had baseline OIs were more likely to develop TB as compared with those without baseline OIs. This may be due to the presence of OIs during ART initiation will increases piles burden, which resulted from drug-drug interaction and side effects which, resulted synergic effects with HIV. This scenario contributes to further weakening of the immune system [30].

Moreover, patients who had a low baseline Hgb levels $(<10 \mathrm{~g} / \mathrm{dl})$ were more likely to develop TB as compared to those with normal Hgb levels $(\geq 10 \mathrm{~g} / \mathrm{dl})$. Supportive findings were reported from previous studies conducted in different regions of Ethiopia [20-22, 34]. that the results in these studies found that advancing WHO disease stage presence of anemia also increased as a result of immunosuppression and reduction of bone marrow cell production [34].

Lastly, taking IPT was another independent predictor of tuberculosis among HIV positive adults on ART. Patients who had not taken IPT were more likely to develop $\mathrm{TB}$ as compared to those who took IPT. This finding is congruent with previous studies conducted in different parts of Ethiopia [15, 16, 20, 34], which may reflect the role of IPT in reducing the occurrence of TB among PLHIV $[14,36]$. As a result, all HIV positive individuals who have no evidence of active TB infection should be taking IPT to prevent TB infection.

\section{Public health implications}

The results of this study are a critical knowledge input for policy makers and program planners designing various $\mathrm{TB}$ control programs. Besides, results obtained from this study will be helpful for health care professionals working in the area of TB/HIV control and prevention unit of Debre Markos Referral Hospital. Additionally, the study provides insights into further intervention studies.

\section{Limitations of the study}

This study has some limitations that must be considered before interpreting results. As the study was conducted through reviewing of records, it did not include important predictors of TB like housing conditions, household incomes, viral loads, and substance use due to incomplete recording system. In addition, study subjects who had incomplete data were excluded from the study. This could undermine or overestimate the incidence of TB. Furthermore, since this study was a facility-based study it does not capture HIV-positive individuals who are out of care (at the community level). The study also focused on adults only; hence, results might not be mirrored in pediatric patient groups.

\section{Conclusion}

The study found a high rate of TB occurrence as compared to previous studies. Baseline OIs, being ambulatory and bedridden, advanced disease stage, low Hgb level, and not taking IPT were predictive of TB. Besides, a high rate of TB occurrence was observed in the first 6 months of ART follow-up. Therefore, based on our findings, we Suggest emphasis and close follow-up should be given for the first 6 months of ART follow-up. Moreover, early detection and treatment of OIs like TB should receive special attention. Furthermore, provision of IPT for HIV positive patients should be strengthened. 


\section{Abbreviations}

AIDS: Acquired Immune Deficiency Syndrome; ART: Antiretroviral Therapy; CDC: Centers for Diseases Control and Prevention; CPT: Co-trimoxazole Preventive Therapy; HAART: Highly Active Antiretroviral Therapy; Hgb: Hemoglobin; HIV: Human Immunodeficiency Virus; PLHIV: People Living with Human Immunodeficiency Virus; TB: Tuberculosis; WHO: World Health Organization

\section{Acknowledgments}

The authors extended their special thanks for both data collectors and supervisor. The authors also would like to acknowledge Mr. Fasil Wagnew (MSc) for his constructive comments and suggestions.

\section{Authors' contributions}

BT: conception of the research idea, study design, data collection, analysis and interpretation, and manuscript write-up. GDK, NMA, MWM, YTH, PP, and AA: analysis and interpretation, and manuscript write-up. All authors have read and approved the final manuscript.

\section{Funding}

Not applicable.

\section{Availability of data and materials}

The data sets used and/or analyzed during the current study are available from the Corresponding author on reasonable request.

\section{Ethics approval and consent to participate}

Ethical clearance was obtained from an Institutional Review Committee of Debre Markos University, College of Health Science, and Department of Public Health. Besides, a permission letter was also secured from Debre Markos Referral Hospital. As the study was conducted by retrospective reviewing medical records of HIV-positive adults, informed oral or written consent from the participants was not feasible. Therefore, the Institutional Review Committee formally waived consent. The main reason of ethics waiver was since the study used patient medical records, the individual participants were not subjected to any harm as much as confidentiality is kept. To maintain confidentiality, names or unique ART numbers were not included in the data extraction format. Moreover, collected data were not disclosed to anyone other than principal investigators.

\section{Consent for publication}

Not applicable.

\section{Competing interests}

The authors declare that they have no competing interests

\section{Author details}

${ }^{1}$ Debre Markos Referral Hospital, Debre Markos, Ethiopia. ${ }^{2}$ College of Health Science, Debre Markos University, P.O. Box 269, Debre Markos, Ethiopia. ${ }^{3}$ College of Nursing, University of Saskatchewan, Saskatoon, Canada. ${ }^{4}$ School of Life Sciences and Bioengineering, Nelson Mandela African Institute of Science and Technology, Arusha, Tanzania. ${ }^{5}$ Faculty of Health, University of Technology Sydney, Sydney, Australia.

Received: 8 July 2019 Accepted: 7 November 2019

Published online: 27 November 2019

\section{References}

1. Frehiwot N, Mizan K, Seble M, Fethia K, Tekalign M, Zelalem T. National guidelines for comprehensive HIV prevention, care and treatment. Addis Ababa: Ministry of Health; 2014

2. Federal Ministry of Health of Ethiopia: Implementation Guideline for TB/HIV Collaborative Activities in Ethiopia. 2007 Available at http://www.who.int/ hiv/pub/guidelines/ethiopia.pdf.

3. Lawn SD, Meintjes G, Mcllleron H, Harries AD, Wood R. Management of HIVassociated tuberculosis in resource-limited settings: a state-of-the-art review. BMC Med. 2013;11(1):253

4. World Health Organization: Global Tuberculosis Report 2018. 2018. Available from https://www.who.int/tb/publications/global_report/gtbr2018_main_ text_28Feb2019.pdf?ua=1. Accessed date 2 Sept 2019
5. Beauté J, Dara M, Pd C, Ehsani S, Gozalov O, Hovanesyan A, Ködmön C, Molnarova B, Boom M, van der Werf M. Tuberculosis surveillance and monitoring in Europe 2017; 2017.

6. World Health Organization: Global tuberculosis report 2016. Accessed from https://www.shareweb.ch/site/Health/publiclibrary/Library\%20external/2 016\%20Global\%20Tuberculosis\%20Report.pdf. Accessed 07 Aug 2019.

7. Centers for Diseases control and prevention (CDC): Global HIV \& Tuberculosis Ethiopia Country Profile available at https://www.cdc.gov/ globalhivtb/where-we-work/ethiopia/ethiopia.html . In.; last reviewed: August 29, 2019. Accessed 06 Aug 2019.

8. Corbett EL, Marston B, Churchyard GJ, De Cock KM. Tuberculosis in subSaharan Africa: opportunities, challenges, and change in the era of antiretroviral treatment. Lancet. 2006:367(9514):926-37.

9. Gao J, Zheng P, Fu H. Prevalence of TB/HIV co-infection in countries except China: a systematic review and meta-analysis. PLoS One. 2013:8(5):e64915.

10. Manosuthi W, Wiboonchutikul S, Sungkanuparph S. Integrated therapy for HIV and tuberculosis. AIDS Res Ther. 2016;13(1):22.

11. Muthamia OG, Chege PM. Determinants of adherence to anti retroviral therapy among adults living with HIV in urban low income settings: a case of Kayole division in Nairobi County, Kenya. Survival. 2011;10:11.

12. Lemos LA, Feijão AR, Gir E, MTG G. Quality of life aspects of patients with HIV/ tuberculosis co-infection. Acta Paulista de Enfermagem. 2012;25(SPE1):41-7.

13. Karambu S, Matiru V, Kiptoo M, Oundo J. Characterization and factors associated with diarrhoeal diseases caused by enteric bacterial pathogens among children aged five years and below attending lgembe District hospital, Kenya. Pan Afr Med J. 2013;16:37.

14. Alemu YM, Awoke W, Wilder-Smith A. Determinants for tuberculosis in HIVinfected adults in Northwest Ethiopia: a multicentre case-control study. BMJ Open. 2016;6(4):e009058.

15. Assebe LF, Reda HL, Wubeneh AD, Lerebo WT, Lambert SM. The effect of isoniazid preventive therapy on incidence of tuberculosis among HIVinfected clients under pre-ART care, Jimma, Ethiopia: a retrospective cohort study. BMC Public Health. 2015;15(1):346.

16. Dowdy DW, Golub JE, Saraceni V, Moulton LH, Cavalcante SC, Cohn S, Pacheco AG, Chaisson RE, Durovni B. Impact of isoniazid preventive therapy for HIV-infected adults in Rio de Janeiro, Brazil: an epidemiological model. J Acquir Immune Defic Syndr (1999). 2014;66(5):552.

17. Organization WH. The use of co-Trimoxazole prophylaxis for HIV-related infections among adults, adolescents and children. Geneva: WHO Press; 2013.

18. Sterling TR, Lau B, Zhang J, Freeman A, Bosch RJ, Brooks JT, Deeks SG, French A, Gange S, Gebo KA. Risk factors for tuberculosis after highly active antiretroviral therapy initiation in the United States and Canada: implications for tuberculosis screening. J Infect Dis. 2011;204(6):893-901.

19. Kassa A, Teka A, Shewaamare A, Jerene D. Incidence of tuberculosis and early mortality in a large cohort of HIV infected patients receiving antiretroviral therapy in a tertiary hospital in Addis Ababa, Ethiopia. Trans R Soc Trop Med Hyg. 2012;106(6):363-70.

20. Ahmed A, Mekonnen D, Kindie M. Incidence and predictors of tuberculosis among adult people living with HIV/AIDS in Afar public health facilities, Northeast Ethiopia. AIDS. 2015;1:3-10

21. Alene KA, Nega A, Taye BW. Incidence and predictors of tuberculosis among adult people living with human immunodeficiency virus at the University of Gondar Referral Hospital, Northwest Ethiopia. BMC Infect Dis. 2013;13(1):292.

22. Dalbo M, Tamiso A. Incidence and predictors of tuberculosis among HIV/ AIDS infected patients: a five-year retrospective follow-up study. Adv Infect Dis. 2016;6(02):70.

23. Federal Democratic Republic of Ethiopia Ministry of Health. In: Ababa A, editor. National comprehensive Tuberculosis, Leprosy and TB/HIV training manual for Health Care Workers; 2016.

24. The Ethiopian Fedral Mlinistry of Health. National ART guidlines for prevention, care and treatment: Ministry of health Ethiopia. Addis Ababa: 2017.

25. Ministry of Health E: National Comprehensive HIV Care and Treatment Training for Health care Providers. 2014

26. Saraceni V, Durovni B, Cavalcante SC, Cohn S, Pacheco AG, Moulton LH, Chaisson RE, Golub JE. Survival of HIV patients with tuberculosis started on simultaneous or deferred HAART in the THRio cohort, Rio de Janeiro, Brazil. Braz J Infect Dis. 2014;18(5):491-5.

27. Pathmanathan I, Dokubo EK, Shiraishi RW, Agolory SG, Auld AF, Onotu D, Odafe S, Dalhatu I, Abiri O, Debem HC. Incidence and predictors of 
tuberculosis among HIV-infected adults after initiation of antiretroviral therapy in Nigeria, 2004-2012. PLoS One. 2017;12(3):e0173309.

28. Enju L, Makubi A, Drain P, Spiegelman D, Sando D, Nan L, Chalamilla G, Sudfeld $C$, Hertzmark E, Fawzi W. Tuberculosis incidence rate and risk factors among HIV-infected adults with access to antiretroviral therapy in Tanzania. AIDS (London, England). 2015;29(11):1391.

29. Melkamu H, Seyoum B, Dessie Y. Determinants of tuberculosis infection among adult HIV positives attending clinical care in western Ethiopia: a case-control study. AIDS Res Treat. 2013;2013.

30. Lawn SD, Badri M, Wood R. Tuberculosis among HIV-infected patients receiving HAART: long term incidence and risk factors in a south African cohort. Aids. 2005;19(18):2109-16

31. Purohit V, Bora V, Ramdeo R, Rewari B. Immune reconstitution inflammatory syndrome after initiation of antiretroviral therapy for HIV. J Indian Acad Clin Med. 2010:11(2):301-304.

32. Bonnet MM, Pinoges LL, Varaine FF, Oberhauser BB, Do O'Brien D, Kebede YY, Hewison CC, Zachariah RR, Ferradini LL. Tuberculosis after HAART initiation in HIV-positive patients from five countries with a high tuberculosis burden. Aids. 2006;20(9):1275-9.

33. Habtamu Oljira MI. Determinants of Active Tuberculosis among HIV-Positive Adults Attending Clinical Care in Ambo general hospital and Gedo hospital, West Shoa Zone, Oromia, Ethiopia (unmatched case-controlstudy). J Med Physiol Biophys. 2015;33(ISSN):2422-8427.

34. Kibret KT, Yalew AW, Belaineh BG, Asres MM. Determinant factors associated with occurrence of tuberculosis among adult people living with HIV after antiretroviral treatment initiation in Addis Ababa, Ethiopia: a case contro study. PLoS One. 2013;8(5):e64488.

35. Mitku AA, Dessie ZG, Muluneh EK, Workie DL. Prevalence and associated factors of TB/HIV co-infection among HIV infected patients in Amhara region, Ethiopia. Afr Health Sci. 2016;16(2):588-95.

36. Ethiopian Public Health Institute (EPHI): Report on National TB/HIV Sentinel Surveillance April 2010-June 2015. 2015, Available https://www.ephi.gov.et/ images/pictures/Final_National_TB HIV_Sentinel_Surveillance_OCT_20_ FE2015_(1)\%20(1).pdf.

\section{Publisher's Note}

Springer Nature remains neutral with regard to jurisdictional claims in published maps and institutional affiliations.

Ready to submit your research? Choose BMC and benefit from:

- fast, convenient online submission

- thorough peer review by experienced researchers in your field

- rapid publication on acceptance

- support for research data, including large and complex data types

- gold Open Access which fosters wider collaboration and increased citations

- maximum visibility for your research: over $100 \mathrm{M}$ website views per year

At $\mathrm{BMC}$, research is always in progress.

Learn more biomedcentral.com/submissions 